\title{
Regulation of transcripts encoding ADAMTS-1 (a disintegrin and metalloproteinase with thrombospondin-like motifs-1) and progesterone receptor by human chorionic gonadotropin in equine preovulatory follicles
}

\author{
D Boerboom ${ }^{1,2}$, D L Russell ${ }^{2}$, J S Richards ${ }^{2}$ and J Sirois ${ }^{1}$ \\ ${ }^{1}$ Centre de Recherche en Reproduction Animale, Faculté de Médecine Vétérinaire, Université de Montréal, CP 5000, Saint-Hyacinthe, Québec, \\ Canada J2S 7C6 \\ ${ }^{2}$ Department of Molecular and Cellular Biology, Baylor College of Medicine, One Baylor Plaza, Houston, Texas 77030, USA
}

(Requests for offprints should be addressed to J Sirois; Email: siroisje@ medvet.umontreal.ca)

\begin{abstract}
One member of a new family of metalloproteinases, a disintegrin and metalloproteinase with thrombospondin-like motifs-1 (ADAMTS-1), has been found to be expressed and hormonally induced in granulosa cells of ovulating rodent follicles. Furthermore, the targeted disruption of the ADAMTS-1 gene resulted in ovarian defects associated with severely impaired fertility. While these data demonstrate the importance of ADAMTS-1 in rodent ovarian physiology, the potential role of ADAMTS-1 in the ovulatory process of monoovulatory species remains unknown. The objectives of this study were to clone the equine ADAMTS-1 primary transcript and to study its regulation during human chorionic gonadotropin (hCG)-induced ovulation. A 3573 bp follicular cDNA library clone was isolated and found to encode a nearly complete, highly conserved ADAMTS-1 homologue. Real-time RT-PCR analysis detected this transcript in diverse tissues, including previously unreported sites of ADAMTS-1 expression such as the male reproductive tract, the follicular theca interna and the mature corpus luteum. The tissue distribution of the progesterone receptor (PR), a known regulator of ADAMTS-1 expression in rodent preovulatory follicles, was found to overlap that of ADAMTS-1 in some tissues. A study of the regulation of follicular ADAMTS-1 and PR mRNAs during the hCG-induced ovulatory process revealed distinct patterns of regulation in granulosa cells and in theca interna. In granulosa cells, ADAMTS-1 mRNA was found to be induced at $12 \mathrm{~h}$ post-hCG $(P<0.05)$, followed by a return to basal levels by $30 \mathrm{~h}$ and a re-increase at 33-39 h $(P<0.05)$. A concomitant increase in PR mRNA $(P<0.05)$ was observed at $12 \mathrm{~h}$ post-hCG. In theca interna, abundant ADAMTS-1 mRNA was detected at all timepoints, and levels increased transiently at $33 \mathrm{~h}$ post-hCG $(P<0.05)$, whereas no significant change was observed in PR mRNA. Together, these data demonstrate for the first time the hormonally regulated ovarian expression of ADAMTS-1 in a monoovulatory species, and identify a novel biphasic regulation of ADAMTS- 1 in granulosa cells and a regulated expression in theca interna that were not previously observed in rodents.
\end{abstract}

Journal of Molecular Endocrinology (2003) 31, 473-485

\section{Introduction}

The expulsion of the oocyte at the moment of ovulation is dependent upon the localized breakdown of the ovarian follicle. For this to occur, it is thought that a proteolytic degradation mechanism activated by the luteinizing hormone (LH) surge acts to breach the connective tissues of the follicle wall (Tsafriri \& Reich 1999). This theory has led researchers to propose numerous different enzymes as potential direct mediators of proteolysis or components of cascades leading to their activation (Espey \& Lipner 1994, Richards et al. 1998, Tsafriri \& Reich 1999).

Among the first of these were the tissue-type and urokinase-type plasminogen activators (tPA and 
uPA), which are induced by LH and could serve to activate collagenase (Richards et al. 1998, Tsafriri \& Reich 1999). However, the generation of $\mathrm{tPA} / \mathrm{uPA}$ double knockout mice whose ovulation rate is only slightly reduced (Leonardsson et al. 1995) suggests either that these may not be essential for ovulation, or that other functionally redundant mechanisms can compensate for their loss. Attention has also been focused on the matrix metalloproteinase (MMP) family, many of which are expressed in the ovary (Curry \& Osteen 2001). Gene expression and zymographic analyses of proteolytic activity during the periovulatory period have implicated interstitial collagenase (MMP-1, MMP-13 in rats), the gelatinases (MMP-2 and -9) and possibly the stromelysin-like MMP-19 in the breakdown of the follicle wall (Richards et al. 1998, Hagglund et al. 1999, Tsafriri \& Reich 1999, Robker et al. 2000b, Gurry \& Osteen 2001, Gurry et al. 2001). In addition, MMP-14, which activates and is coordinately regulated with MMP-2 in the ovary, may also play a role (Sato et al. 1994, Liu et al. 1998, Hagglund et al. 1999). The significance of these data has, however, been blurred by additional findings, such as the expression and activity of many of these enzymes at other stages of follicular and luteal development (Robker et al. 2000b, Curry \& Osteen 2001), and that MMP-2 and -9 null mice are fertile (Itoh et al. 1997, Vu et al. 1998, Richards et al. 2002). Furthermore, several tissue inhibitors of metalloproteinases (TIMPs) are expressed at various stages of the ovarian cycle, and TIMP-1 expression is induced by LH coordinately with several MMPs (Hagglund et al. 1999, Tsafriri \& Reich 1999, Gurry \& Osteen 2001, Simpson et al. 2001). The exact role (if any) of each of these genes in ovulation therefore remains largely speculative. A more recently identified proteolytic enzyme expressed in the ovarian follicle is a disintegrin and metalloproteinase with thrombospondin-like motifs-1 (ADAMTS-1) (Robker et al. 2000b). Originally described as being selectively expressed in a murine colon adenocarcinoma cell line and up-regulated during the inflammatory response (Kuno et al. 1997), ADAMTS-1 was subsequently shown to associate with the extracellular matrix (ECM) (Kuno \& Matsushima 1998) and to possess angio-inhibitory activity (Vazquez et al. 1999). Insight into its physiological functions was gained by its targeted disruption, which resulted in multisystemic abnormalities including uterine and ovarian defects associated with severely impaired fertility (Shindo et al. 2000).

A potential role for ADAMTS-1 in ovarian physiology was also revealed by other groups seeking to identify LH-induced genes and progesterone receptor (PR) transcriptional targets (Espey et al. 2000, Robker et al. $2000 a, b$ ). Progesterone has long been known to be a key paracrine mediator of ovulation in rodents, as its synthesis increases dramatically during the ovulatory process, along with ovarian PR expression (Richards 1994). Furthermore, pharmacological inhibition of its synthesis and action blocks ovulation (Tsafriri \& Reich 1999) and, most importantly, PR null mice show an anovulatory phenotype (Lydon et al. 1995). While many mechanisms could account for the importance of progesterone in ovulation, a current hypothesis maintains that the preovulatory increase in progesterone could trigger the proteolytic degradation of the follicle wall (Tsafriri \& Reich 1999). Consistent with this, differential display RT-PGR identified ADAMTS-1 as a gene that is transiently induced in the granulosa cell layer of ovarian follicles following the LH surge, and at a time also subsequent to PR induction (Espey et al. 2000, Richards et al. 2002). It was further demonstrated that ADAMTS-1 induction is sensitive to the progesterone synthesis inhibitor epostane (Espey et al. 2000) and is markedly impaired in PR null mice (Robker et al. 2000a,b), thereby situating this event downstream of the induction of progesterone synthesis and PR expression. While it can be inferred from these studies that ADAMTS-1 is a likely key player in the ovulatory process, its exact role in the follicle remains unknown (Richards et al. 2002). Furthermore, all studies of ovarian ADAMTS-1 expression reported thus far have been limited to rodents, rendering unknown the importance of ADAMTS-1 in the ovarian physiology of large monoovulatory species. In view of this, the general objective of this study was to determine if ADAMTS-1 is expressed and hormonally regulated in equine preovulatory follicles, thereby providing an important monoovulatory model system for the future study of ovarian ADAMTS-1 function. The specific objectives were to clone and characterize the equine ADAMTS-1 primary transcript, and to study its regulation as well as that of PR in preovulatory follicles during human chorionic gonadotropin (hCG)-induced ovulation. 


\section{Materials and methods}

\section{Materials}

Sigma Fast DAB tablets were purchased from Sigma Chemical Co. (St Louis, MO, USA); hGG was purchased from The Buttler Co. (Columbus, $\mathrm{OH}$, USA); $\left[\alpha-{ }^{32} \mathrm{P}\right]$ deoxycytidine $5^{\prime}$-triphosphate (dCTP) was obtained from Perkin-Elmer Life Sciences (Woodbridge, Canada); QuikHyb hybridization solution and the ExAssist/SOLR system were purchased from Stratagene Cloning Systems (La Jolla, CA, USA); Prime-a-Gene labeling system was purchased from Promega Corp. (Madison, WI, USA); synthetic oligonucleotides and TRIzol total RNA isolation reagent were purchased from Invitrogen Life Technologies (Burlington, Canada); dye-labeled hybridization probes were obtained from Synthegen, LLC (Houston, TX, USA) and TIB Mol-Biol (Adelphia, NJ, USA); Vectastain Elite ABC Kit was obtained from Vector Laboratories, Inc. (Burlingame, CA, USA); Antigen Retrieval Citra Plus Solution was purchased from BioGenex Laboratories, Inc. (San Ramon, CA, USA); LightCycler RNA Amplification Kit for Hybridization Probes was obtained from Roche Diagnostics (Laval, Canada); QuantiTect Probe RT-PCR Kit was purchased from Qiagen Inc. (Mississauga, Canada).

\section{Isolation of equine tissues and RNA extraction}

Equine preovulatory follicles and corpora lutea were isolated from Standardbred and Thoroughbred mares at specific stages of the estrous cycle as previously described (Boerboom \& Sirois 1998). Briefly, mares were teased daily with a pony stallion for detection of estrus, and ovarian follicular development was monitored by transrectal realtime ultrasonography. The ovulatory process was induced by administration of hCG (2500 IU, i.v.) once the dominant follicle had reached a diameter of $35 \mathrm{~mm}$. Ovariectomy was performed via colpotomy on the standing animal under neuroleptanalgesia as described (Boerboom \& Sirois 1998) at $0,12,24,30,33,36$ and $39 \mathrm{~h}$ post-hCG $(n=4$ or 5 follicles/timepoint). In this model, the normal expected time of ovulation in mares is 39-42 h after hCG treatment (Boerboom \& Sirois 2001). Corpora lutea were isolated on day 8 of the estrous cycle $(n=3$; day $0=$ day of ovulation). Each follicular sample detailed in the text therefore represents the single preovulatory follicle from a given estrous cycle of a single mare. All animal procedures were approved by the institutional animal care and use committee (Comité de Déontologie Animale de l'Université de Montréal) and were conducted in accordance with the guidelines described in The UFAW Handbook on the Care and Management of Laboratory Animals as well as FRAME's guidelines on papers involving the use of laboratory animals, as promulgated by the Society for Endocrinology.

The preovulatory follicles from recovered ovaries were dissected into preparations of follicle wall (theca interna with attached granulosa cells) or further dissected into separate isolates of granulosa cells and theca interna as described (Boerboom \& Sirois 2001). In some instances, follicle wall, granulosa cell and theca interna samples were derived from the same follicle. Male gonadal tissues were obtained from the Centre Hospitalier Universitaire Vétérinaire (Université de Montréal) following routine castration procedures. Uterine tissues were endometrial biopsy samples removed from pregnant or nonpregnant mares at precisely cycle day 15, and were a gift from Dr Denis Vaillancourt (Université de Montréal, Canada). All other tissues were obtained at a local slaughterhouse. Total RNA was isolated from tissues using TRIzol reagent (Life Technologies) according to manufacturer's instructions, using a Kinematica PT 1200G Polytron Homogenizer (Fisher Scientific, Montréal, Canada) and quantified by spectrophotometry according to standard protocols (Sambrook et al. 1989).

\section{Cloning and characterization of the equine ADAMTS-1 cDNA and protein}

The equine ADAMTS-1 cDNA was isolated from a previously described expression library (Boerboom \& Sirois 1998) made from RNA extracted from an equine preovulatory follicle isolated during estrus, $36 \mathrm{~h}$ after hCG treatment. Screening of approximately 150000 phage plaques was performed as directed in the ZAP-cDNA Synthesis Kit instruction manual (Stratagene), using a $1.5 \mathrm{~kb}$ fragment of murine ADAMTS-1 genomic DNA (which includes a part of the $3^{\prime}$ coding region (D L Russell \& J S Richards, unpublished observation)). The probe was labeled with $\left[\alpha-{ }^{32} \mathrm{P}\right] \mathrm{dCTP}$ using the Prime-a-Gene labeling 
system (Promega) to a final specific activity greater than $1 \times 10^{8}$ c.p.m./ $/$ g DNA, and hybridization was performed at $55^{\circ} \mathrm{C}$ with QuikHyb hybridization solution (Stratagene). Of approximately 100 positive clones obtained, ten were selected for plaque purification through secondary and tertiary screening. The Ex-Assist/SOLR system (Stratagene) was then used to perform in vivo excision to obtain the cloned cDNAs inserted within the pBluescript plasmid. Sequencing was performed by the Service de Séquençage de l'Université Laval (Québec, Canada) using vectorbased T7 and T3 oligonucleotide primers and ADAMTS-1 sequence-specific primers (Invitrogen).

Nucleotide analyses were performed using MacDNASIS software version 2.0 (Hitachi, Hialeah, FL, USA), and comparisons with GenBank databases were performed online by standard nucleotide-nucleotide BLAST analyses (Altschul et al. 1997) at the National Center for Biotechnology Information website (www.ncbi.nlm.nih.gov). Protein sequence comparisons were made online by standard protein-protein BLAST analyses (Altschul et al. 1997) at the same website; homologous proteins were aligned using the CLUSTALW v1 7 software (Thompson et al. 1994) online at the Protein Information Resource of the National Biomedical Research Foundation (pir.georgetown.edu/pirwww) (Wu et al. 2002). Functional domains within the ADAMTS-1 protein were identified by online BLAST analyses (Altschul et al. 1997) against the ProDom 2001.3 Protein Domain Database at the ProDom project website (http://prodes.toulouse.inra.fr/prodom/ doc/prodom.html).

\section{Real-time RT-PCR analysis}

Quantification of ADAMTS-1, PR and glyceraldehyde-3-phosphate dehydrogenase (GAPDH) transcripts was performed by real-time RT-PCR analysis using the LightCycler system (Roche) and either the LightCycler RNA Amplification Kit for Hybridization Probes (Roche) or the QuantiTect Probe RT-PGR Kit (Qiagen), following the manufacturer's instructions. RT and PGR reactions were conducted sequentially in a single capillary reaction tube using $100 \mathrm{ng}$ of each RNA sample and the equine gene-specific oligonucleotide pairs 5'-TGGTG TAACA TCGAG GACTG TCG-3' and 5'-AGATG CATTT CGTCG
GCAAA TACC-3' for ADAMTS-1, 5'-ACTTC TTAAT AGAAT TCGTT TGGAA G-3' and 5'-GAACT AGAAA GAAGT CGTTT TGGCG-3' for PR (GenBank accession number AF007798) and 5'-ATCAG CATCT TCGAG GAGCG AGA-3' and 5'-GTCTT CTGGG TGGCA GTGAT GG-3' for GAPDH (GenBank AF157626), resulting in the generation of 348, 126 and $341 \mathrm{bp}$ products respectively. Cycling conditions using the kit supplied by Roche were one cycle of $55^{\circ} \mathrm{C}$ for $20 \mathrm{~min}$ (RT step), one cycle of $95^{\circ} \mathrm{C}$ for $30 \mathrm{~s}$ (denaturation step), 45 cycles of $95^{\circ} \mathrm{C}$ for $5 \mathrm{~s}, \quad 59^{\circ} \mathrm{C}$ (ADAMTS- 1 ) or $55^{\circ} \mathrm{C}$ (GAPDH) for $15 \mathrm{~s}$ and $72{ }^{\circ} \mathrm{C}$ for $20 \mathrm{~s}$ (PGR step), and one cycle of $40^{\circ} \mathrm{C}$ for $30 \mathrm{~s}$ (cooling step). Cycling conditions using the Qiagen kit were one cycle of $55^{\circ} \mathrm{C}$ for $20 \mathrm{~min}$, one cycle of $95^{\circ} \mathrm{C}$ for $15 \mathrm{~min}, 35$ (PR) or 45 (ADAMTS- 1 and GAPDH) cycles of $95^{\circ} \mathrm{C}$ for $5 \mathrm{~s}, 59{ }^{\circ} \mathrm{C}$ for $30 \mathrm{~s}$ and $72{ }^{\circ} \mathrm{C}$ for $30 \mathrm{~s}$, and one cycle of $40{ }^{\circ} \mathrm{C}$ for $30 \mathrm{~s}$. The accumulation of PGR products was quantified at every cycle by use of the dye-labeled, gene-specific oligonucleotide hybridization probes 5'-AGGGG AGTGT GTAAA AGCTG GCTG (fluorescein)-3' and 5'-(LG red 640) GACGG CATGA TAGAC TCCAA AAAGA AG (phosphate)-3' for ADAMTS-1, 5'-CAGTT TGAAG AGATG AG ATG AAACT ACA(fluorescein)-3' and 5'-(LC red 640) TAGAG AGCTG ATCAA GGGGA TTGGT (phosphate)-3' for PR and 5'-CGAAG GTGAT CCATG ACGAC TTTG(fluorescein)-3' and $5^{\prime}$-(LG red 640) CATGG TGGAG GGACT CATGA CGAC (phosphate)-3' for GAPDH. Binding of the probes to their complementary sequences on the PCR products permits fluorescence resonance energy transfer between donor (fluorescein) and acceptor (LG red 640) dye molecules. Fluorescence vs cycle number data curves were compared with standard curves generated by the PCR amplification of plasmid DNA samples of known concentration, thereby permitting the calculation of an absolute number of copies of target RNA molecules in each sample.

\section{Statistical analysis}

All mRNA quantification data were normalized by dividing ADAMTS-1 or PR transcript copy numbers by their corresponding GAPDH copy numbers, which were quantified in separate 
real-time RT-PCR reactions. In the case of follicular tissues, for which multiple samples were analyzed for each timepoint, results are expressed as means \pm s.E.M. $(n=3-5$ follicles (i.e. mares)/ timepoint). When Levene's test demonstrated homogeneity of variance, one-way ANOVA was used to test the effect of time (after hCG) on ADAMTS-1:GAPDH or PR:GAPDH transcript level ratios. When ANOVAs indicated significant differences $(P<0 \cdot 05)$, Dunnett's test was used for multiple comparisons with the control $(0 \mathrm{~h}$ post$\mathrm{hCG}$ ). If Levene's test showed heterogeneity of variance, data were transformed to logarithms before ANOVA analysis. In cases when logarithmic transformation did not result in homogeneity of variance, the nonparametric Wilcoxon test was used for multiple comparisons with the control $(0 \mathrm{~h}$ post-hCG). By this method, the nonparametric test was applied to all data sets except those presented in Fig. 4A and the PR data in Fig. 5B. Statistical analyses were performed using JMP software (SAS Institute, Inc., Cary, NC, USA).

\section{Results}

\section{Cloning and characterization of the equine ADAMTS-1 transcript and protein}

To clone the equine ADAMTS-1 primary transcript, a fragment of the murine ADAMTS-1 gene was used to probe a previously described equine follicular expression library (Boerboom \& Sirois 1998). This resulted in the isolation of ten cDNA clones encoding the equine ADAMTS-1 homologue, the longest of which (clone A5) was sequenced extensively (Fig. 1, GenBank accession number AF541975). The 3573 bp cDNA included 1292 bp of 3 '-untranslated region, preceded by an open reading frame of $2281 \mathrm{bp}$ that was found to be incomplete at its $5^{\prime}$ end, when aligned with its human homologue (Fig. 1A). Attempts to isolate the $5^{\prime}$ end of the equine ADAMTS-1 transcript using a variety of library cloning, 5'-RACE and RT-PCR techniques proved to be unfruitful. This was attributed to the $>80 \%$ G-C content of the first $100 \mathrm{bp}$ of the equine cDNA clone, a structural feature that would easily block efficient reverse transcription. By homology with the known murine ADAMTS-1 gene structure (GenBank accession number AB001735), clone A5 apparently lacks most of the sequences derived from exon I.
When translated, cDNA clone A5 was found to encode a nearly complete ADAMTS-1 protein which, by comparison with its species homologues, lacks only the propeptide and signal sequence regions (Fig. 2). The region encompassing the key structural features (catalytic domain, disintegrinlike domain, spacer region and thrombospondin type I domains) was shown to be highly conserved, demonstrating 95, 92 and $92 \%$ identity to the human, mouse and rat ADAMTS-1 proteins respectively. Sites of proteolytic processing of the ADAMTS-1 protein by furin and MMPs previously identified in other species (Kuno et al. 1999, Rodriguez-Manzaneque et al. 2000) were found to be conserved in the equine homologue. In addition, three of the four putative N-linked glycosylation sites identified in the murine homologue (Kuno et al. 1997) were also found to be present in equine ADAMTS-1.

\section{Tissue distribution of ADAMTS-1 and PR transcripts}

To study the distribution of ADAMTS-1 transcripts in equine tissues, steady-state mRNA levels were quantified by real-time RT-PCR. ADAMTS-1 transcripts were detected in a wide variety of non-ovarian tissues, several of which had not been previously identified as sites of ADAMTS-1 expression in any species, including lymph nodes, epididymis and testis (Fig. 3). As PR had previously been identified as an upstream regulator of ovarian ADAMTS-1 expression (Espey et al. 2000, Robker et al. 2000a,b), analyses of its transcript levels were performed on the same tissues. While the distribution of PR was found to overlap that of ADAMTS-1 in some tissues, PR but not ADAMTS-1 was detected in the glandular stomach. Conversely, in the liver and skin, ADAMTS-1 mRNA was detected in absence of PR. Furthermore, it should be noted that while PR and ADAMTS-1 mRNA levels were comparable in uterine and ovarian tissues (Figs 3 and 4), PR transcripts were generally two orders of magnitude less abundant than ADAMTS-1 in all other tissues, as indicated in the labels of the axis in Fig. 3.

To determine if ADAMTS-1 transcripts are present in mature ovarian follicles and whether their levels are regulated by the LH surge, preovulatory follicles were isolated before and after the administration of an ovulatory dose of $\mathrm{hCG}$, 
A

\begin{tabular}{|c|c|c|}
\hline ORF (2281 bp) & & Equine cDNA library \\
\hline ORF (2853 bp) & & Human ADAMTS- 1 \\
\hline
\end{tabular}

B

1 GGATGACGAG ACCCAGCCCT CGAGGGGCGC GGAGCCGGAG GGCCAGGACG 51 CCGGGACGCA GTGGGCGCCG CGGGACAGGG CCCCGCAGCG CGCCGGACGG 101 CCAACAGGAA CTGGAAGCAT AAGAAAGAAG CGATTTGTGT CCAGCCCCCG 151 ATATGTGGAA ACCATGCTTG TGGCTGACCA GTCTATGGCA GAGTTCCACG 151 ATATGTGGAA ACCATGCTTG TGGCTGACCA GTCTATGGCA GAGTTCCACG 251 TTATACAAAC ACCCCAGCAT TCGGAATTCA GTTAGCCTGG TGGTGGTGAA 301 GATCCTAGTC ATCTATGAGG AACAGAAGGG GCCCGAAGTG ACTTCCAATG 351 CTGCTCTCAC TCTGCGGAAT TTCTGCAACT GGCAAAAGCA GCACAACCCG 401 CCCAGTGACC GGGATGCGGA GCACTATGAC ACAGCGATTC TTTTCACCCG 451 ACAGGATTTG TGTGGGGCCC AGACATGTGA TACTCTTGGG ATGGCTGATG 501 TTGGAACTAT ATGTGATCCC AGCAGAAGCT GCTCGGTCAT AGAAGATGAT 551 GGTTTACAAG CTGCCTTCAC CACAGCCCAT GAATTAGGCC ACGTGTTTAA 601 CATGCCACAT GATGATGCAA AGCAATGTGC CAGCATTAAT GGTGTCAACC 601 CATGCCACAT GATGATGCAA AGCAATGTGC CAGCATTAAT GGTGTCAACC 701 CCTTGGTCTC CCTGCAGCGC CTACATGATT ACATCATTTC TGGATAATGG 751 TCACGGTGAA TGTTTGATGG ACAAGCCCCA GAGCCCCATA CAGCTCCCCT 801 CTGATCTCCC CGGGACCTTG TATGATGCCA ACCGGCAATG CCAGTTCACG 851 TTTGGGGAGG AGTCCAAACA CTGCCCGGAT GCAGCCAGCA CGTGCACGAC 901 CCTCTGGTGC ACTGGCACTT CTGGCGGGTT GCTGGTGTGC CAAACCAAAC 951 ACTTCCCTTG GGCAGATGGC ACCAGCTGTG GAGAAGGGAG ATGGTGTGTC 1001 AATGGCAAGT GTGTGAACAA GACCGACAGG AAGCATTTTG ATACTCCTGT 1051 TCATGGAAGC TGGGGGCCGT GGGGGCCCTG GGGAGACTGT TCGAGAACAT 1101 GTGGTGGAGG AGTTCAGTAT ACAATGAGGG AATGTGACAA CCCAGTGCCA 1151 AAGAATGGAG GGAAGTACTG TGAAGGCAAG CGCGTGCGCT ACAGGTCGTG

1201 TAACATCGAG GACTGTCCGG ATAATAATGG GAAAACCTTT AGAGAGGAAC

1251 AATGTGAGGC TCACAATGAA TTTTCGAAAG CTTCCTTTGG GAGTGGGCCT

1301 GCGGTGGAGT GGACACCCAA GTATGCTGGA GTCTCACCAA AGGACAGGTG

1351 CAAGCTCATC TGTCAAGCCA AAGGCATTGG CTACTTCTTC GTTTTGCAGC

1401 CCAAGGTGGT AGATGGTACT CCATGTAGCC CCGATTCCAC CTCTGTCTGC

1451 GTGCAAGGGC AGTGTGTAAA AGCTGGCTGT GACCGCATCA TAGACTCCAA

1501 AAAGAAGTTT GATAAATGCG GTATTTGCGG AGGAAATGGA TCTACATGCA

1551 AGAAAATATC CGGATCAGTT ACTAGTGCAA AACCTGGATA TCATGATATC

1601 GTCACAATTC CAACTGGAGC CACAAACATT GAAGTGAAAC AACGGAATCA

1651 GAGGGGATCC AGAAATAATG GAAGCTTTCT TGCCATCAAA GCTGCTGATG

1701 GCACATACAT CCTGAATGGT GACTTCACTT TGTCCACTTT AGAACAAGAC

1751 ATTACGTACA AAGGTAGTGT CTTGAGGTAC AGTGGCTCTT CTGCAGCGTT

1801 GGAAAGAATT CGCAGCTTTA GTCCTCTCAA AGAGCCCTTA ACCATCCAGG

1851 TCCTTACAGT GGGCAATGCC CTTCGACCGA AAATTAAATA CACATACTTT

1901 GTGAAGAAGA AGAAGGAATC TTTCAATGCC ATCCCTACTT TCTCAGAATG

1951 GGTCATCGAA GAGTGGGGCG AATGTTCCAA GTCATGTGGA CAGGGTTGGC

2001 AGAGAAGACT GGTAGAGTGC CGAGACATCA ATGGGCAGCC AGCTTCCGAG

2051 TGTGCGAAGG AAGTGAAGCC AGCCAGCACC AGACCTTGTG CAGACCTGCC

2101 TTGTCCCCGC TGGCAGCTGG GGGATTGGTC GCCATGTTCC AAGACTTGTG

2151 GGAAGGGTTA CAAAAAGAGA ACCTTGCAGT GTCTGTCCCA CGATGGGGGG

2201 GTGTTGTCTC AAGAGAGCTG CGATCCTTTA AAGAAACCCA AACATTACAT

2251 AGACTTTTGC ACCATGGCAG AATGCAGTTA Agcaatgtca gtgttgaggg

2301 aaaagtaaag tgtggaaggg ctgatgcact gaaatcaaga aggctggagg

2351 aatccagtgt accttgccgg tgatcaacaa ggtgtgtcta tgagttagga

2401 gactataggt aggtagaaaa gaagttagat cgtcagaata tcctgccagt

2451 tacaaacttg atagggtagt taatgaggat tattaatctc tgagcaatga

2501 tatagcatga taaaggccca gggcattatt atcatccctt ttgttacatc

2551 tatgacaagt taaaaaaaa atagaaacaa ttgtcaaaat aatttaaga

2601 aatattacaa tccctgtttc ctggtactga ttaatactt tgtatcatgg

2651 ggattaggaa atgaaaagca ggaaaagat gagaatttta gttaagatg

2701 tggcttattt cacctcgcta acaatagagg gagaaaggag tatgtatagg

2751 gtctttggcc agcactgcca tggctgctat ggtttcagag aatgctatct

2801 tttctaccca gcagtaagaa ttcaacattg accagcatga gagaatgtg

2851 taacaacgtc caatgactcc gtctgtactt tettgtgcca ttcttgtgtc

2901 tttatttgtc aattcattt gacaaggaaa caattccgtg tatttgtaag

2951 aatgcattga gtctacaaga gggaaaaaa gcagcaatgt atcagatgct

3001 gggaaaata actagaggag gcaggatgag gtcagtacct cctaccattc

3051 gttcctcett atgtaagcct getttaggaa tgtggatgtg gaaaacagt

3101 gtgtgtctca aggaagtcag taacaccaca caaaaggat gtaatgccag

3151 aataagtatg gggtgcatag aatggggtcc ccagttttg gggacactgc

3201 agtcacttgt ctcacagtgg ggaggctact gaggggtagc gggtccatcc

3251 ccagcagctg gtccaacagt catatcctgg tgaatgtctg ttcagctct

3301 caactatgaa agagaatatg actttttcca tgtgtatata gtaaatata

3351 ttactataaa ttctatgtac tttataagta ttggtttgtg tgttccttct

3401 aagaaggact atagtttgta ataaatgcct ataataacat atttatttt

3451 atacattct ttctaatgat aatcttta agttatatcg ctttgtaaa

3501 agaacatata aaaatagag tatttataca atatatgtta ctagaaataa

3551 taaaaagaca ctttttgaaa aaa

Figure 1 Molecular cloning and characterization of the nucleotide sequence of the equine ADAMTS-1 primary transcript. (A) Schematic representation of the isolated cDNA clone, aligned with its human homologue (GenBank accession number NM_006988). ORF=open reading frame, UTR=untranslated region. (B) Complete nucleotide sequence of the equine ADAMTS-1 cDNA clone. The ORF is indicated by uppercase letters, the translation termination codon (TAA) is highlighted in bold, the $3^{\prime}$-UTR is indicated by lowercase letters, putative polyadenylation signals are underlined, and numbers on the left refer to the first nucleotide on that line. The nucleotide sequence has been assigned the GenBank accession number AF541975. 
Horse

Human

Mouse

Rat

Horse

Human

Mouse

Rat

Horse

Human

Mouse

Rat

Horse

Human

Mouse

Rat

Horse

Human

Mouse

Rat

Horse

Human

Mouse

Rat

Horse

Human

Mouse

Rat

Horse

Human

Mouse

Rat

Horse

Human

Mouse

Rat

Horse

Human

Mouse

Rat

signal sequence

MQRAVPEGFG RRKLGSDMGN AERAPGSRSF GPVPTLLLLA A---ALLAVS DALGRPSEED EELVVPELER APGHGT--TR LRLHAFDQQL DLELRPDSSF

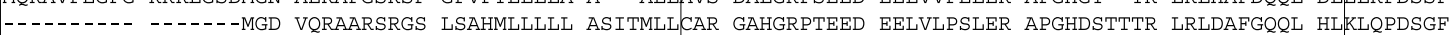
MQPEVPLGSG KLKPCSDMGD IQRAAKFRSS QSAHMLLLLL ASITMLLCVR GAHGRPTEED EELVLPSLER ARGHDS-TTL LRLDAFGQQL HLKLQPDSGF

propeptide

LAPGFTLQNV GRKSGSETP- LPET-DLAHC FYSGTVNGDP SSAAALSLCE GVRGAFYLLG EAYFIQPLP- AASERLATAA PGEKPPAPLQ FHLLRRNRQG LAPGFTLQTV GRSPGSEAQH LDPTGDLAHC FYSGTVNGDP GSAAALSLCE GVRGAFYLQG EEFFIQPAPG VATERLAPAV PEEESSARPQ FHILRRRRRG LAPGFTLQTV GRSPGSEAQH LDPTGDLAHC FYSGTVNGDP SSAAALSLCE GVRGAFYLQG EEFFIQPAPA VATERLVPAE PKEESIAPPR FHILRRRRRG

-..-D DETQPSRGAE PE--.---G QDAGTQWAPR DRAPQRAGRP TGTGSI $\overrightarrow{\overline{\text { RKKR }}}$ FVSSPRYVET MLVADQSMAE FHGSGLKHYL LTLFSVAARL

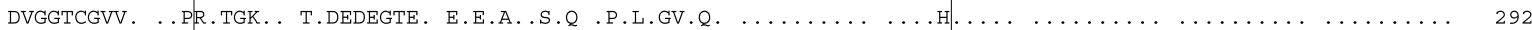

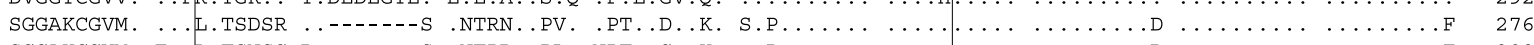

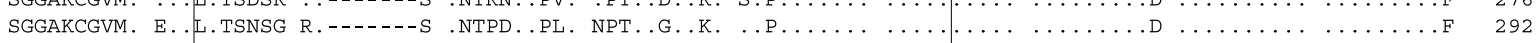

\section{metalloprotease domain}

YKHPSIRNSV SLVVVKILVI YEEQKGPEVT SNAALTLRNF CNWQKQHNPP SDRDAEHYDT AILFTRQDLC GAQTCDTLGM ADVGTICDPS RSCSVIEDDG

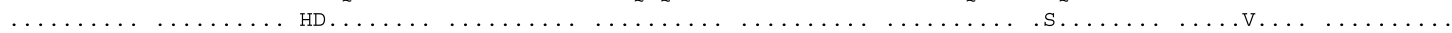

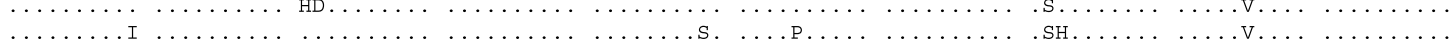

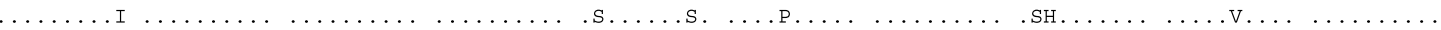

LQAAFTTAHE LGHVFNMPHD DAKQCASING VNRDSHMMAS MLSNLDRSQP WSPCSAYMIT SFLDNGHGEC LMDKPQSPIQ LPSDLPGTLY DANRQCQFTF

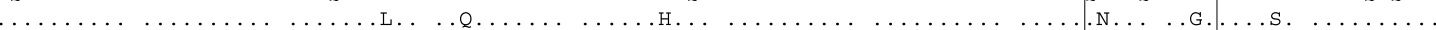

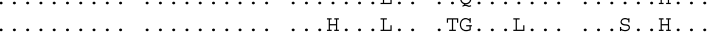

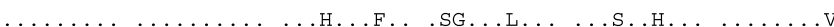

V. $\cdots \cdots$

disintegrin-like domain

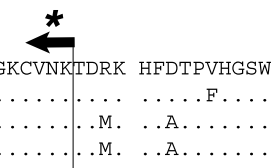

GEESKHCPDA ASTCTTLWCT GTSGGLLVCQ TKHFPWADGT SCGEGRWCVN
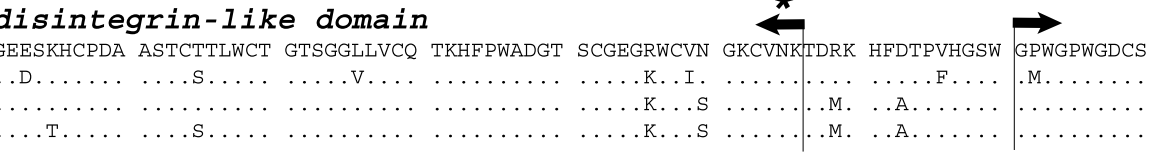

thrombospondin

\section{type I domain}

NGGKYCEGKR VRYRSCNIED CPDNNGKTFR EEQCEAHNEF SKASFGSGPA VEWTPKYAGV SPKDRCKLIC QAKGIGYFFV LQPKVVDGTP CSPDSTSVCV

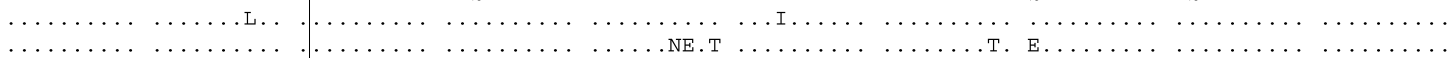

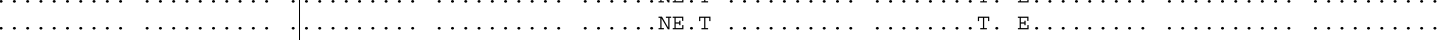

QGQCVKAGCD RIIDSKKKFD KCGICGGNGS TCKKISGSVT SAKPGYHDIV TIPTGATNIE VKQRNQRGSR NNGSFLAIKA ADGTYILNGD FTLSTLEQDI

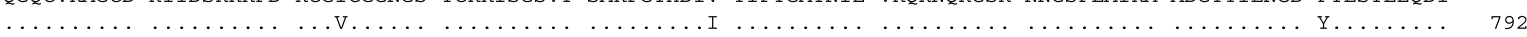

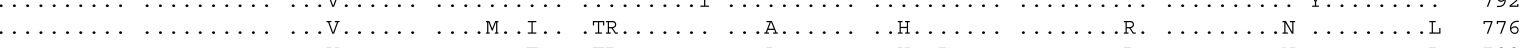

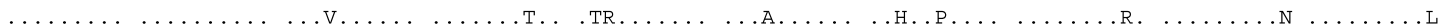

thrombospondin type I TYKGSVLRYS GSSAALERIR SFSPLKEPLT IQVLTVGNAL RPKIKYTYFV KKKKESFNAI PTFSEWVIEE WGECSKSCGQ GWQRRLVECR DINGQPASEC

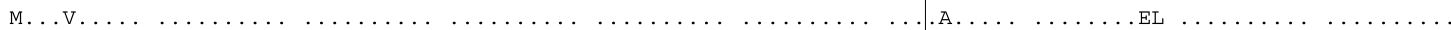

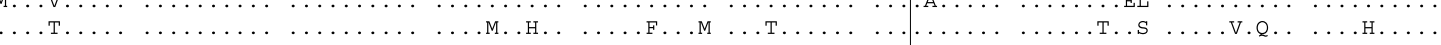

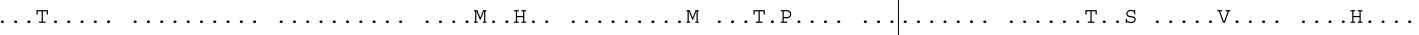

domain

thrombospondin type I domain

AKEVKPASTR PCADLPCPRW QLGDWSPCSK TCGKGYKKRT LQCLSHDGGV LSQESCDPLK KPKHYIDFCT MAECS

$\begin{array}{lll}\ldots \ldots & \ldots \ldots \\ \ldots \ldots & \ldots \ldots\end{array}$

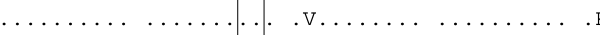

. K. . . . . . . . . . . . . . I LT L.

Figure 2 Domain structure of the equine ADAMTS-1 protein and comparison with known homologues. The deduced amino acid sequence of the equine ADAMTS-1 protein is aligned with the human (GenBank accession number AF207664), mouse (NM_024400) and rat (NM_009621) homologues. Identical residues are indicated by a printed period. Specific regions and domains are bordered by vertical lines with arrows and identified overhead in boldface type. Putative furin (RKKR) and MMP (AKPG) proteolytic processing sites are double-overlined, and the specific point of cleavage is indicated with an inverted arrow. The neutral zinc metallopeptidase zinc-binding region contained within the metalloprotease domain is indicated with a dashed double overline. Putative N-linked glycosylation sites are indicated with asterisks. Numbers on the right refer to the last amino acid residue on that line.

and steady-state ADAMTS-1 mRNA levels were quantified (Fig. 4A). In contrast to previous reports in rodents (Espey et al. 2000, Robker et al. 2000a), expression of ADAMTS-1 mRNA was detected in equine follicles before the $\mathrm{LH}$ surge (i.e. $0 \mathrm{~h}$ post-hCG). Although ADAMTS-1 transcript levels 


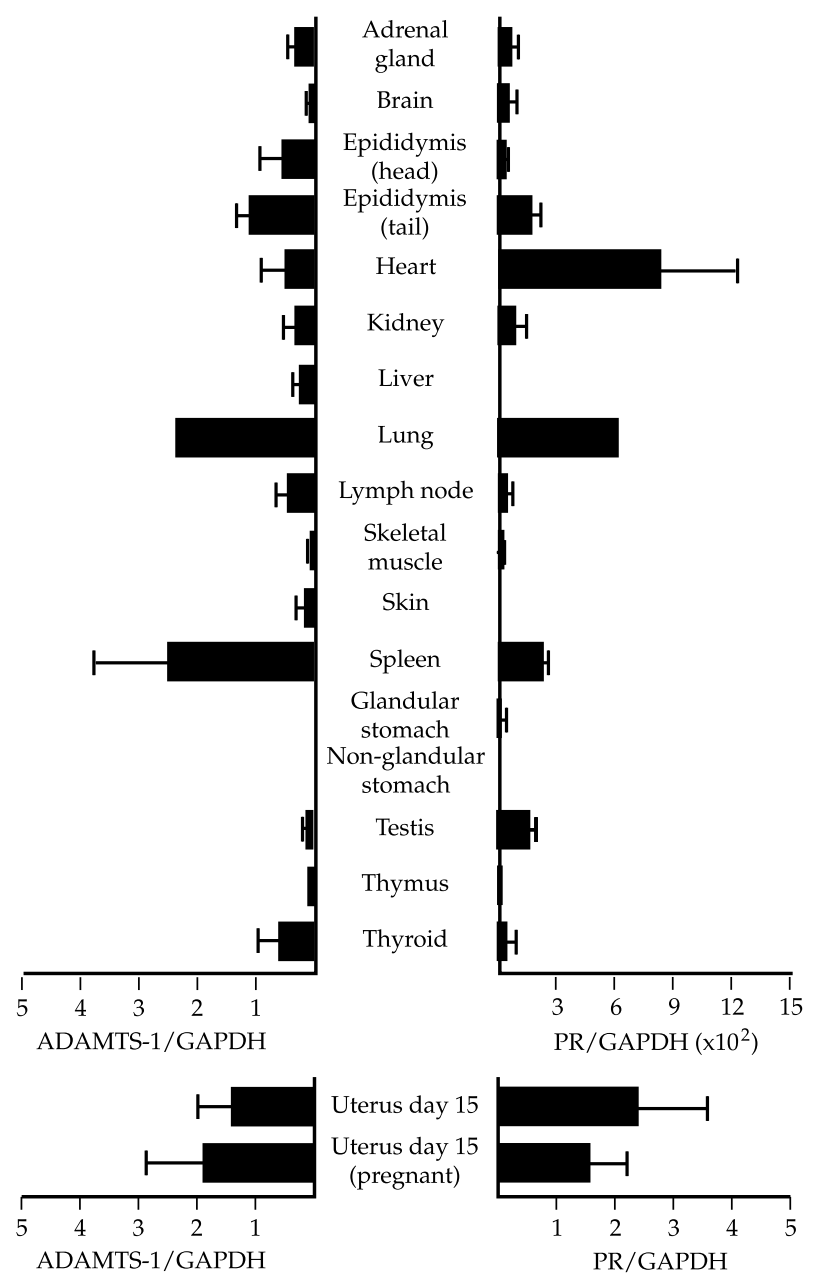

Figure 3 ADAMTS- 1 and $P R$ transcripts in various tissues. ADAMTS-1, PR and GAPDH mRNA levels were quantified by real-time RT-PCR using the LightCycler system, and data were normalized by calculating ADAMTS-1:GAPDH or PR:GAPDH copy number ratios. Three RNA samples were used for all tissues except for lung and thymus, for which $n=2$. Data are expressed as means (bars) \pm S.E.M. (error bars), except where $n=2$ (expressed as means only).

appeared to increase approximately 2-fold at $12 \mathrm{~h}$ post-hCG, no statistically significant differences could be detected when compared with $0 \mathrm{~h}$ $(P>0 \cdot 10)$. Also unexpectedly, the highest amounts of ADAMTS-1 mRNA of all tissues analyzed were detected in the mature (day 8) corpus luteum, a tissue that had not been previously reported to express ADAMTS-1 in any species. Unlike ADAMTS-1, a significant increase in PR transcript levels was noted at $12 \mathrm{~h}$ post-hCG $(P<0 \cdot 05)$, after which they rapidly decreased, and reached their
A. Ovarian ADAMTS-1 expression

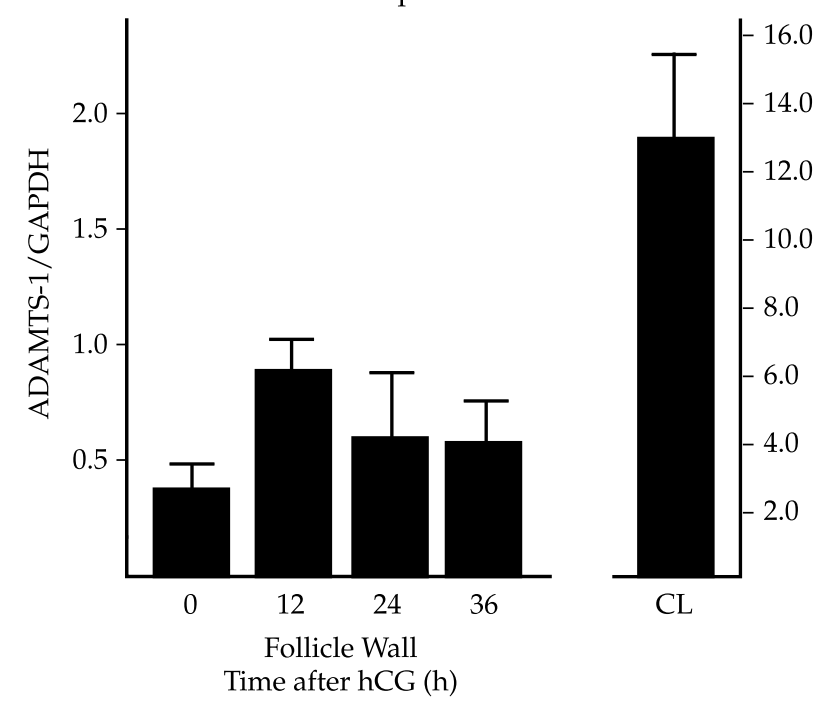

B. Ovarian PR expression

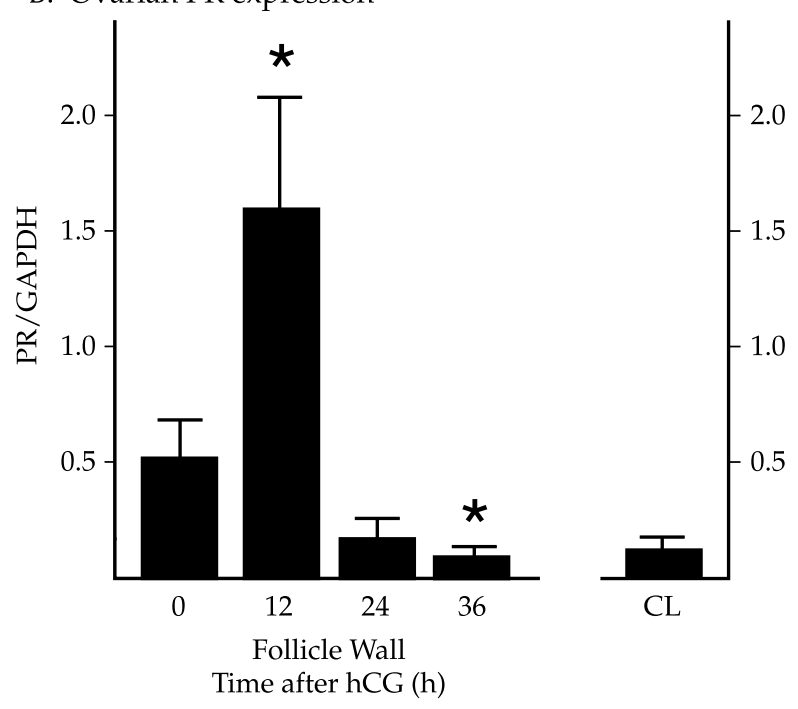

Figure 4 Regulation of ADAMTS- 1 and PR mRNAs in equine preovulatory follicles during hCG-induced ovulation. ADAMTS-1, PR and GAPDH mRNA levels were quantified by real-time RT-PCR using the LightCycler system, and data were normalized by calculating ADAMTS-1:GAPDH or PR:GAPDH copy number ratios. Five RNA samples were used for all timepoints issues except for $\mathrm{t}=0 \mathrm{~h}(n=4)$ and corpora lutea $(C L)(n=3)$. Data are expressed as means (columns) \pm S.E.M. (error bars). Follicle wall mRNA preparations were obtained from preovulatory follicles at the indicated times after the administration of an ovulatory dose of hCG, CL were isolated on day 8 of the estrous cycle. Statistically significant difference $(P<0.05)$ from the untreated preovulatory follicle (i.e. $0 \mathrm{~h}$ post-hCG) is indicated with an asterisk $\left(^{*}\right)$. 
A. Granulosa Cells

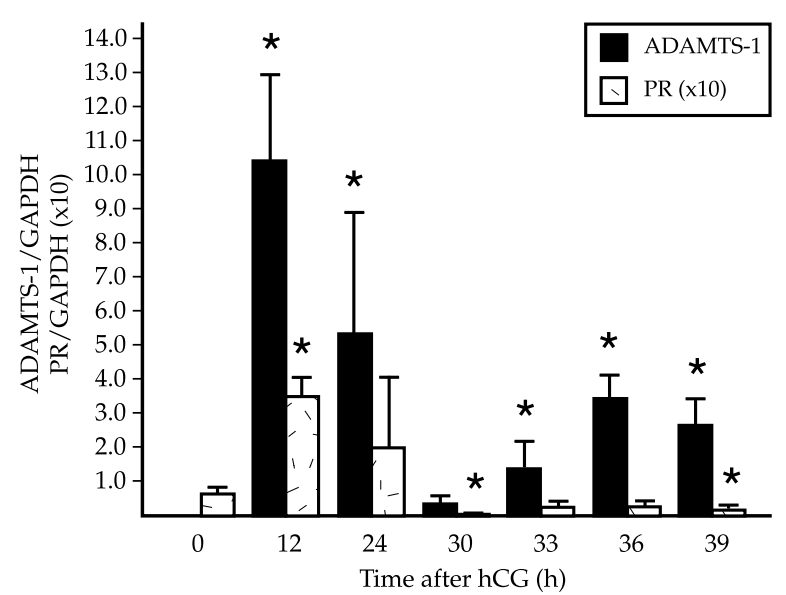

B. Theca Interna

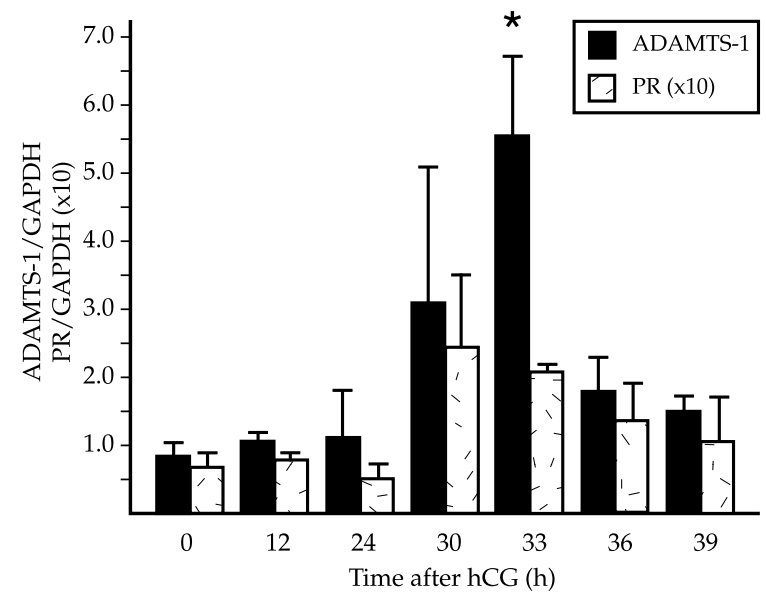

Figure 5 Regulation of ADAMTS-1 and PR mRNAs in isolated granulosa cells and theca interna during hCG-induced ovulation. Isolated granulosa cell (A) and theca interna (B) mRNA preparations were obtained from preovulatory follicles at the indicated times after the administration of an ovulatory dose of hCG. ADAMTS-1, PR and GAPDH mRNA levels were quantified using the LightCycler system, and the data were normalized by calculating ADAMTS-1:GAPDH or PR:GAPDH copy number ratios. Data are represented as the means of these ratios (columns) \pm S.E.M. (error bars). Four samples were analyzed per timepoint, except (A) $t=33 \mathrm{~h}$ (ADAMTS-1 and PR), $\mathrm{t}=36 \mathrm{~h}$ (PR only) and $\mathrm{t}=39 \mathrm{~h}$ (PR only), and (B) $\mathrm{t}=0 \mathrm{~h}$ and $\mathrm{t}=33 \mathrm{~h}$ (ADAMTS- 1 and PR), where $n=3$. Statistically significant difference from $0 \mathrm{~h}$ post-hCG $(P<0.05)$ is indicated with an asterisk $\left({ }^{*}\right)$.

lowest point at $36 \mathrm{~h}$ (Fig. 4B). PR mRNA was also readily detectable in the corpus luteum, although at much lower abundance than what was observed in $12 \mathrm{~h}$ post-hCG follicle wall.

\section{Regulation of ADAMTS-1 and PR mRNAs in granulosa cells and theca interna}

To investigate the unexpected absence of ADAMTS-1 mRNA regulation in the follicle wall during the ovulatory process, real-time RT-PCR analyses were performed on separate isolates of granulosa cells and theca interna. In granulosa cells, ADAMTS-1 mRNA was found to be markedly induced at $12 \mathrm{~h}$ post-hGG $(P<0 \cdot 05)$, followed by a return to basal levels by $30 \mathrm{~h}$ (Fig. $5 A)$. Interestingly, mRNA levels then exhibited a secondary increase that reached a plateau at $36 \mathrm{~h}$ $(P<0 \cdot 05)$. Consistent with its established role as a regulator of ADAMTS-1 expression in rodent granulosa cells, PR mRNA levels were also found to increase significantly at $12 \mathrm{~h}(P<0 \cdot 05)$, and to subsequently decrease to their lowest point at $30 \mathrm{~h}$. However, no significant secondary re-increase in PR mRNA levels $(P>0 \cdot 10)$ was observed thereafter, even though levels appear to rise after $30 \mathrm{~h}$
post-hCG (Fig. 5A). Unlike ADAMTS-1, PR transcripts were detected at $\mathrm{t}=0 \mathrm{~h}$.

In contrast with in situ hybridization data reported in rodents (Espey et al. 2000, Robker et al. $2000 a$ ), theca interna was found to be an important site of equine ovarian ADAMTS-1 expression (Fig. 5B). Appreciable amounts of ADAMTS-1 mRNA were detected at $0 \mathrm{~h}$, accounting for the unexpected levels detected in follicle wall at the same timepoint (Fig. 4A). The pattern of ADAMTS- 1 mRNA regulation by $\mathrm{hCG}$ in theca interna was found to be distinct from what was observed in granulosa cells, with a single, sharp increase in mRNA levels occurring at $33 \mathrm{~h}$ $(P<0 \cdot 05)$, followed by a return to basal levels by 36 h. An apparent 4-fold increase in PR transcript abundance in theca interna was also found to occur late in the ovulatory process (30-33 h post-hCG), but mRNA levels were not found to be significantly different from $0 \mathrm{~h}$ post-hCG $(P>0 \cdot 10)$.

\section{Discussion}

Many of the important advances in our understanding of molecular ovarian physiology have 
been gained through the use of well-established rodent models (Richards 1994). This is clearly due to several technical and practical advantages of working with rodents, not the least of which is the possibility of genetic manipulations (Nishimori \& Matzuk 1996). Despite these advantages, however, the information derived from rodents does not always serve as an accurate predictor of what occurs in large monoovulatory species. This has been demonstrated notably by a recent series of studies in equine preovulatory follicles, which showed that several genes involved in steroidogenesis and ovulation exhibit spatial and temporal expression patterns within the follicle that are different from what has been reported in rodents (Boerboom \& Sirois 1998, 2001, Boerboom et al. 1999, 2000, Kerban et al. 1999a). The present study further emphasizes these differences by demonstrating distinct patterns of ovarian ADAMTS-1 and PR expression and regulation. Notably, the prolonged, biphasic regulation of ADAMTS-1 transcripts by hCG in equine granulosa cells contrasts with its rapid, monophasic induction observed in rodents (Pinter et al. 1996, Espey et al. 2000, Robker et al. 2000a,b). Also, while the theca interna is clearly an important site of ADAMTS-1 and PR expression in equine preovulatory follicles, in situ hybridization studies suggest their expression in the rodent ovary is limited to granulosa cells (Pinter et al. 1996, Espey et al. 2000, Robker et al. $2000 a, b)$. These data may reflect distinct roles for these genes in follicular development and luteinization in each species, and further highlight the importance of studying both mono- and polyovulatory animal models of ovarian physiology.

The analyses of the tissue distribution of ADAMTS-1 mRNA reported herein feature several unexpected findings. Most notably, this is the first report of the detection of ADAMTS-1 mRNA in lymph nodes, the male reproductive tract, the mature corpus luteum and the theca interna cell layer of the ovarian follicle (Vazquez et al. 1999, Miles et al. 2000). The presence of high levels of ADAMTS-1 mRNA were particularly unexpected in the two latter tissues, considering that the corpus luteum undergoes remodeling that necessitates extensive neovascularization, and ADAMTS-1 mRNA levels increase in the theca interna at a time associated with the presence of increased numbers of thecal blood vessels (Kerban et al. 1999b). These data are thus in apparent contradiction with the proposed anti-angiogenic activity of ADAMTS-1 (Vazquez et al. 1999). Ovarian ADAMTS-1 would somehow need to exert its biological function without inhibiting angiogenesis, perhaps by post-translational modification. Alternatively, its anti-angiogenic properties may simply be overwhelmed at certain times during the ovulation/luteinization process by a preponderance of pro-angiogenic activities present in the follicle wall and corpus luteum. It should be noted, however, that other biological evidence downplaying the anti-angiogenic properties of ADAMTS-1 has been reported. For instance, ADAMTS-1 expression has no apparent impact on vascular density in certain tumors (Masui et al. 2001), and the ADAMTS-1 ${ }^{-/}$mouse features a paradoxical deficiency in adrenal medulla capillary formation (Shindo et al. 2000, Tang 2001). The role of ADAMTS-1 in angiogenesis thus may be complex and tissue-specific.

The present study is the first to report the primary structure of the ADAMTS- 1 transcript and protein in a monoovulatory nonprimate species. Among the most highly evolutionarily conserved elements identified in the equine ADAMTS-1 protein is the region encompassing the thrombospondin type I domains and the spacer region. This region is found in ADAMTS proteins and the ECM-associated glycoproteins punctin (ADAMTSL-1), lacunin and papilin, and has recently been termed the 'papilin cassette' (Nardi et al. 1999, Kramerova et al. 2000, Hirohata et al. 2002). As the murine ADAMTS-1 papilin cassette has been demonstrated to function as an ECMbinding domain (Kuno \& Matsushima 1998, Kuno et al. 1999), this cassette may permit the ADAMTS, ADAMTSL, lacunin and papilin protein families to associate with the ECM. In the case of ADAMTS-1, binding to the ECM presumably serves to target its proteolytic activity to where its substrates are located. As ADAMTS-1 has been shown to degrade the large aggregating proteoglycans aggrecan, brevican and versican (Sandy et al. 2001, Richards et al. 2002), it has been proposed that ADAMTS-1 could act upon follicular proteoglycans which inhibit certain growth factors and gonadotropins, and could thereby increase their bioactivity (Richards et al. 2002). Alternatively, proteoglycan cleavage could also impact upon cell migration by modulating cell-cell and cell-ECM adhesion, a function that 
the ADAMTS-1 disintegrin domain may also perform by disrupting the binding of cellular integrins to ECM proteins (Salustri et al. 1999, Evans 2001). Consistent with this, equine granulosa cells become noticeably detached from each other and from their basement membrane within $12 \mathrm{~h}$ post-hCG, in a manner concurrent with ADAMTS-1 induction (Kerban et al. 1999b). This could serve to disperse the luteinizing granulosa cells within the mucoid web that accumulates in the antrum during the ovulatory process (Kerban et al. 1999b), thereby permitting proper formation of the corpus luteum. Perhaps ADAMTS-1 expression then persists in the corpus luteum so as to permit its formation, remodeling and/or regression. Validation of these hypotheses will obviously require the identification of the biologically relevant ovarian substrates of ADAMTS-1.

The coordinate regulation of $\mathrm{PR}$ and ADAMTS-1 mRNAs by hCG in equine granulosa cells during the initial, transient induction phase at $12 \mathrm{~h}$ post-hCG is in apparent agreement with the proposed function of $\mathrm{PR}$ as a regulator of ADAMTS-1 expression in rodents (Espey et al. 2000, Robker et al. 2000a,b). However, the absence of a significant secondary rise in $\mathrm{PR}$ in granulosa cells and of a significant increase of PR mRNA in theca interna preclude any definitive association between the two transcripts in the equine follicle. Additional studies involving larger numbers of follicles and/or investigating the regulation of ADAMTS-1 and PR proteins will help resolve this issue. Interestingly, a recent study in cattle, another monoovulatory species with a long ovulatory process (28-30 h post-gonadotropin-releasing hormone $(\mathrm{GnRH})$ ), demonstrated a biphasic pattern of $\mathrm{PR}$ mRNA regulation in cows, with primary and secondary increases observed at 6 and $24 \mathrm{~h}$ post-GnRH respectively (Jo et al. 2002). These data differ from what is reported herein in that the kinetics of PR mRNA regulation in equine granulosa cells were more drawn-out, likely reflecting the longer equine ovulatory process in mares (39-42 h post-hCG). Also, the elevated levels of PR expression observed before hCG treatment in mares (i.e. at $0 \mathrm{~h}$ ) were not observed in cows. This may be caused by the unusually progressive preovulatory rise in circulating gonadotropin levels that occurs in horses (Daels \& Hughes 1993), which could result in PR expression before the ovulatory process is induced. Why this does not in turn lead to appreciable ADAMTS-1 expression in early preovulatory follicle granulosa cells is unknown, and may involve a transcriptional repression mechanism to prevent premature ADAMTS-1 expression.

In summary, this study describes for the first time the structure of the equine ADAMTS-1 transcript, as well as its distinct regulatory patterns in two separate follicular cell types during the hCGinduced ovulatory process. The biphasic pattern of ADAMTS-1 mRNA regulation in granulosa cells suggests the presence of both early and late hormonally induced gene regulatory events, at least in species with long ovulatory processes. In this regard, the exceptionally protracted equine ovulatory process permitted a high-resolution timecourse analysis of gene regulation. This study therefore highlights the value of the horse as a model system for the study of ovarian gene regulation, a model which will certainly serve to further elucidate the role of ADAMTS-1 in monoovulatory ovarian physiology.

\section{Acknowledgements}

The authors would like to thank Dr D Vaillancourt (Université de Montréal, Canada) for his generous gift of uterine biopsy samples, as well as Dr A K Goff (Université de Montréal, Canada) for his assistance with statistical analyses. This study was supported by Natural Sciences and Engineering Research Council of Canada grant OPG0171135, and National Institutes of Health grants NIH-HD16229 and SCGPRR-HD-07495. D B is supported by a Fellowship from the Canadian Institutes of Health Research (CIHR), J S is supported by a CIHR Investigator Award.

\section{References}

Altschul SF, Madden TL, Schaffer AA, Zhang J, Zhang Z, Miller W \& Lipman DJ 1997 Gapped BLAST and PSI-BLAST: a new generation of protein database search programs. Nucleic Acids Research 25 3389-3402.

Boerboom D \& Sirois J 1998 Molecular characterization of equine prostaglandin $\mathrm{G} / \mathrm{H}$ synthase-2 and regulation of its messenger ribonucleic acid in preovulatory follicles. Endocrinology 139 $1662-1670$.

Boerboom D \& Sirois J 2001 Equine P450 cholesterol side-chain cleavage and 3 beta-hydroxysteroid dehydrogenase/delta(5)delta(4) isomerase: molecular cloning and regulation of their messenger ribonucleic acids in equine follicles during the ovulatory process. Biology of Reproduction 64 206-215. 
Boerboom D, Kerban A \& Sirois J 1999 Dual regulation of promoter II- and promoter 1f-derived cytochrome P450 aromatase transcripts in equine granulosa cells during human chorionic gonadotropin-induced ovulation: a novel model for the study of aromatase promoter switching. Endocrinology 140 4133-4141.

Boerboom D, Pilon N, Behdjani R, Silversides DW \& Sirois J 2000 Expression and regulation of transcripts encoding two members of the NR5A nuclear receptor subfamily of orphan nuclear receptors, steroidogenic factor- 1 and NR5A2, in equine ovarian cells during the ovulatory process. Endocrinology 141 4647-4656.

Curry TE Jr \& Osteen KG 2001 Cyclic changes in the matrix metalloproteinase system in the ovary and uterus. Biology of Reproduction 64 1285-1296.

Curry TE Jr, Song L \& Wheeler SE 2001 Cellular localization of gelatinases and tissue inhibitors of metalloproteinases during follicular growth, ovulation, and early luteal formation in the rat. Biology of Reproduction 65 855-865.

Daels PF \& Hughes JP 1993 The normal estrous cycle. In Equine Reproduction, pp 121-132. Eds AO McKinnon \& JL Voss. Philadelphia, PA: Lea \& Febiger.

Espey LL \& Lipner H 1994 Ovulation. In The Physiology of Reproduction, pp 725-780. Eds E Knobil \& JD Neill. New York: Raven Press.

Espey LL, Yoshioka S, Russell DL, Robker RL, Fujii S \& Richards JS 2000 Ovarian expression of a disintegrin and metalloproteinase with thrombospondin motifs during ovulation in the gonadotropin-primed immature rat. Biology of Reproduction 62 1090-1095.

Evans JP 2001 Fertilin beta and other ADAMs as integrin ligands: insights into cell adhesion and fertilization. Bioessays 23 628-639.

Hagglund AC, Ny A, Leonardsson G \& Ny T 1999 Regulation and localization of matrix metalloproteinases and tissue inhibitors of metalloproteinases in the mouse ovary during gonadotropin-induced ovulation. Endocrinology 140 4351-4358.

Hirohata S, Wang LW, Miyagi M, Yan L, Seldin MF, Keene DR, Crabb JW \& Apte SS 2002 Punctin, a novel ADAMTS-like molecule, ADAMTSL-1, in extracellular matrix. Fournal of Biological Chemistry 277 12182-12189.

Itoh T, Ikeda T, Gomi H, Nakao S, Suzuki T \& Itohara S 1997 Unaltered secretion of beta-amyloid precursor protein in gelatinase A (matrix metalloproteinase 2)-deficient mice. Fournal of Biological Chemistry 272 22389-22392.

Jo M, Komar C \& Fortune J 2002 Gonadotropin surge induces two separate increases in messenger RNA for progesterone receptor in bovine preovulatory follicles. Biology of Reproduction 67 1981-1988.

Kerban A, Boerboom D \& Sirois J 1999a Human chorionic gonadotropin induces an inverse regulation of steroidogenic acute regulatory protein messenger ribonucleic acid in theca interna and granulosa cells of equine preovulatory follicles. Endocrinology 140 667-674.

Kerban A, Dore M \& Sirois J 19996 Characterization of cellular and vascular changes in equine follicles during hCG-induced ovulation. Fournal of Reproduction and Fertility 117 115-123.

Kramerova IA, Kawaguchi N, Fessler LI, Nelson RE, Chen Y, Kramerov AA, Kusche-Gullberg M, Kramer JM, Ackley BD, Sieron AL, Prockop DJ \& Fessler JH 2000 Papilin in development; a pericellular protein with a homology to the ADAMTS metalloproteinases. Development 127 5475-5485.

Kuno K \& Matsushima K 1998 ADAMTS-1 protein anchors at the extracellular matrix through the thrombospondin type I motifs and its spacing region. Fournal of Biological Chemistry $\mathbf{2 7 3}$ 13912-13917.

Kuno K, Kanada N, Nakashima E, Fujiki F, Ichimura F \& Matsushima K 1997 Molecular cloning of a gene encoding a new type of metalloproteinase-disintegrin family protein with thrombospondin motifs as an inflammation associated gene. Fournal of Biological Chemistry 272 556-562.

Kuno K, Terashima Y \& Matsushima K 1999 ADAMTS-1 is an active metalloproteinase associated with the extracellular matrix. Journal of Biological Chemistry 274 18821-18826.

Leonardsson G, Peng XR, Liu K, Nordstrom L, Carmeliet P, Mulligan R, Collen D \& Ny T 1995 Ovulation efficiency is reduced in mice that lack plasminogen activator gene function: functional redundancy among physiological plasminogen activators. PNAS 92 12446-12450.

Liu K, Wahlberg P \& Ny T 1998 Coordinated and cell-specific regulation of membrane type matrix metalloproteinase 1 (MT1-MMP) and its substrate matrix metalloproteinase 2 (MMP-2) by physiological signals during follicular development and ovulation. Endocrinology 139 4735-4738.

Lydon JP, DeMayo FJ, Funk CR, Mani SK, Hughes AR, Montgomery CA Jr, Shyamala G, Conneely OM \& O'Malley BW 1995 Mice lacking progesterone receptor exhibit pleiotropic reproductive abnormalities. Genes and Development 9 2266-2278.

Masui T, Hosotani R, Tsuji S, Miyamoto Y, Yasuda S, Ida J, Nakajima S, Kawaguchi M, Kobayashi H, Koizumi M, Toyoda E, Tulachan S, Arii S, Doi R \& Imamura M 2001 Expression of METH-1 and METH-2 in pancreatic cancer. Clinical Cancer Research 7 3437-3443.

Miles RR, Sluka JP, Halladay DL, Santerre RF, Hale LV, Bloem L, Thirunavukkarasu K, Galvin RJ, Hock JM \& Onyia JE 2000 ADAMTS-1: a cellular disintegrin and metalloprotease with thrombospondin motifs is a target for parathyroid hormone in bone. Endocrinology 141 4533-4542.

Nardi JB, Martos R, Walden KK, Lampe DJ \& Robertson HM 1999 Expression of lacunin, a large multidomain extracellular matrix protein, accompanies morphogenesis of epithelial monolayers in Manduca sexta. Insect Biochemistry and Molecular Biology 29 883-897.

Nishimori K \& Matzuk MM 1996 Transgenic mice in the analysis of reproductive development and function. Reviews of Reproduction $\mathbf{1}$ 203-212.

Pinter JH, Deep C \& Park-Sarge OK 1996 Progesterone receptors: expression and regulation in the mammalian ovary. Clinical Obstetrics and Gynecology 39424435.

Richards JS 1994 Hormonal control of gene expression in the ovary. Endocrine Reviewes 15 725-751.

Richards JS, Russell DL, Robker RL, Dajee M \& Alliston TN 1998 Molecular mechanisms of ovulation and luteinization. Molecular and Cellular Endocrinology 145 47-54.

Richards JS, Russell DL, Ochsner S \& Espey LL 2002 Ovulation: new dimensions and new regulators of the inflammatory-like response. Annual Review of Physiology 64 69-92.

Robker RL, Russell DL, Espey LL, Lydon JP, O’Malley BW \& Richards JS 2000a Progesterone-regulated genes in the ovulation process: ADAMTS-1 and cathepsin L proteases. PNAS 97 4689-4694.

Robker RL, Russell DL, Yoshioka S, Sharma SC, Lydon JP, O'Malley BW, Espey LL \& Richards JS 2000b Ovulation: a multi-gene, multi-step process. Steroids 65 559-570.

Rodriguez-Manzaneque JC, Milchanowski AB, Dufour EK, Leduc R \& Iruela-Arispe ML 2000 Characterization of METH-1/ADAMTS1 processing reveals two distinct active forms. Journal of Biological Chemistry 275 33471-33479.

Salustri A, Camaioni A, Di Giacomo M, Fulop C \& Hascall VC 1999 Hyaluronan and proteoglycans in ovarian follicles. Human Reproduction Update 5 293-301.

Sambrook J, Fritsch EF \& Maniatis T 1989 Molecular Cloning: a Laboratory Manual, edn 2. Cold Spring Harbor, NY: Cold Spring Harbor Laboratory Press.

Sandy JD, Westling J, Kenagy RD, Iruela-Arispe ML, Verscharen C, Rodriguez-Mazaneque JC, Zimmermann DR, Lemire JM, 
Fischer JW, Wight TN \& Clowes AW 2001 Versican V1 proteolysis in human aorta in vivo occurs at the Glu441-Ala442 bond, a site that is cleaved by recombinant ADAMTS- 1 and ADAMTS-4. Journal of Biological Chemistry 276 13372-13378.

Sato H, Takino T, Okada Y, Cao J, Shinagawa A, Yamamoto E \& Seiki M 1994 A matrix metalloproteinase expressed on the surface of invasive tumour cells. Nature 370 61-65.

Shindo T, Kurihara H, Kuno K, Yokoyama H, Wada T, Kurihara Y, Imai T, Wang Y, Ogata M, Nishimatsu H, Moriyama N, Oh-hashi Y, Morita H, Ishikawa T, Nagai R, Yazaki Y \& Matsushima K 2000 ADAMTS-1: a metalloproteinase-disintegrin essential for normal growth, fertility, and organ morphology and function. Fournal of Clinical Investigation 105 1345-1352.

Simpson KS, Byers MJ \& Curry TE Jr 2001 Spatiotemporal messenger ribonucleic acid expression of ovarian tissue inhibitors of metalloproteinases throughout the rat estrous cycle. Endocrinology 142 2058-2069.

Tang BL 2001 ADAMTS: a novel family of extracellular matrix proteases. International Fournal of Biochemistry and Cell Biology 33 33-44.

Thompson JD, Higgins DG \& Gibson TJ 1994 CLUSTAL W: improving the sensitivity of progressive multiple sequence alignment through sequence weighting, position-specific gap penalties and weight matrix choice. Nucleic Acids Research 22 4673-4680.

Tsafriri A \& Reich R 1999 Molecular aspects of mammalian ovulation. Experimental and Clinical Endocrinology and Diabetes 107 $1-11$.

Vazquez F, Hastings G, Ortega MA, Lane TF, Oikemus S, Lombardo M \& Iruela-Arispe ML 1999 METH-1, a human ortholog of ADAMTS-1, and METH-2 are members of a new family of proteins with angio-inhibitory activity. Fournal of Biological Chemistry 274 23349-23357.

Vu TH, Shipley JM, Bergers G, Berger JE, Helms JA, Hanahan D, Shapiro SD, Senior RM \& Werb Z 1998 MMP-9/gelatinase B is a key regulator of growth plate angiogenesis and apoptosis of hypertrophic chondrocytes. Cell 93 411-422.

Wu CH, Huang H, Arminski L, Castro-Alvear J, Chen Y, Hu ZZ, Ledley RS, Lewis KC, Mewes HW, Orcutt BC, Suzek BE, Tsugita A, Vinayaka CR, Yeh LS, Zhang J \& Barker WC 2002 The Protein Information Resource: an integrated public resource of functional annotation of proteins. Nucleic Acids Research $\mathbf{3 0}$ 35-37.

Received 8 May 2003

Accepted 6 August 2003 